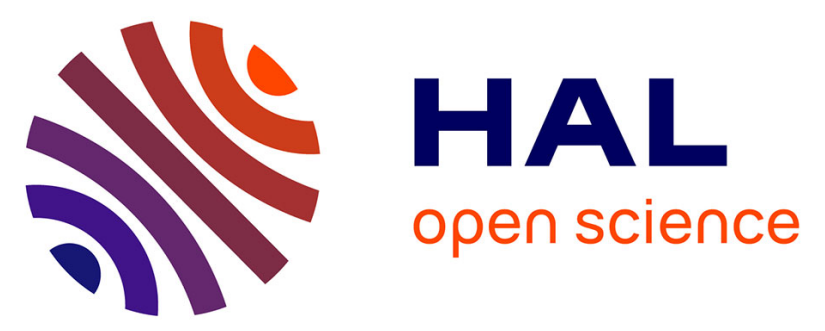

\title{
Evidence of glycemia-lowering effect by a Cynara scolymus L. extract in normal and obese rats
}

Noemi Fantini, Giancarlo Colombo, Antonella Riva, Paolo Morazzoni, Ezio Bombardelli, Mauro A.M. Carai

\section{- To cite this version:}

Noemi Fantini, Giancarlo Colombo, Antonella Riva, Paolo Morazzoni, Ezio Bombardelli, et al.. Evidence of glycemia-lowering effect by a Cynara scolymus L. extract in normal and obese rats. Phytotherapy Research, 2010, 10.1002/ptr.3285 . hal-00613789

\section{HAL Id: hal-00613789 \\ https://hal.science/hal-00613789}

Submitted on 6 Aug 2011

HAL is a multi-disciplinary open access archive for the deposit and dissemination of scientific research documents, whether they are published or not. The documents may come from teaching and research institutions in France or abroad, or from public or private research centers.
L'archive ouverte pluridisciplinaire HAL, est destinée au dépôt et à la diffusion de documents scientifiques de niveau recherche, publiés ou non, émanant des établissements d'enseignement et de recherche français ou étrangers, des laboratoires publics ou privés. 


\section{Evidence of glycemia-lowering effect by a Cynara scolymus L. extract in normal and obese rats}

\begin{tabular}{|r|l|}
\hline Journal: & Phytotherapy Research \\
\hline Manuscript ID: & PTR-10-0189.R3 \\
\hline Diley - Manuscript type: & Short Communication \\
\hline Author: & 02-Jul-2010 \\
\hline & $\begin{array}{l}\text { Complete List of Authors: } \\
\text { Contini, Noemi; C.N.R. Institute of Neuroscience } \\
\text { Riva, Antonella; Indena SpA } \\
\text { Bombani, Paolo; Indena SpA } \\
\text { Carai, Mauro; C.N.R. Insitute of Neuroscience }\end{array}$ \\
\hline \hline Keyword: & $\begin{array}{l}\text { Artichoke (Cynara scolymus L.), Extract of flowering heads, } \\
\text { Glycemia, Zucker rats, Nutraceutical }\end{array}$ \\
\hline \multicolumn{2}{|c}{} \\
\hline
\end{tabular}

\section{(5)holarONE" \\ Manuscript Central}


1

2

3

1 2

3

4

5

6

7 Noemi Fantini ${ }^{1}$, Giancarlo Colombo ${ }^{1}$, Andrea Giori ${ }^{2}$, Antonella Riva ${ }^{2}$, Paolo Morazzoni ${ }^{2}$, Ezio

8 Bombardelli $^{2}$, Mauro A.M. Carai ${ }^{1}$

9

10

$11{ }^{1}$ C.N.R. Neuroscience Institute, Viale Diaz 182, I-09126 Cagliari, Italy, and ${ }^{2}$ Indena S.p.A., Viale in normal and obese rats

\section{Evidence of glycemia-lowering effect by a Cynara scolymus $L$. extract}

12 Ortles 12, I-20139, Milan, Italy.

13

14

15

16 Corresponding author:

17

18 Mauro A.M. Carai

19 C.N.R. Neuroscience Institute

$20 \quad$ Viale Diaz 182

21 I-09126 Cagliari (CA)

22 Italy

23 Phone: +39070302227

24 Fax: +39070 302076

25 e-mail: caraimam@ tiscali.it 


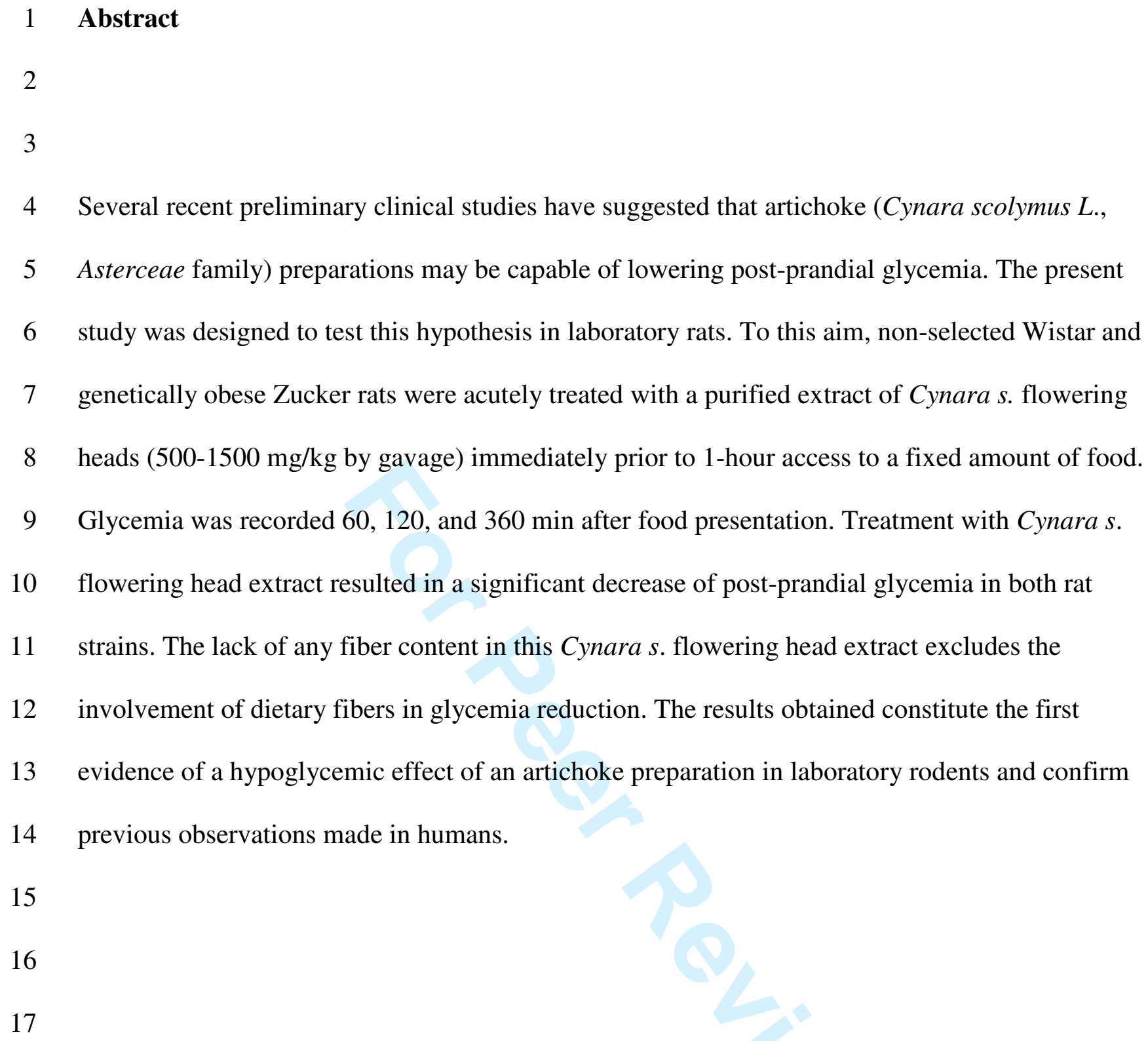


4 Artichokes (Cynara scolymus L., Asterceae family) are an ancient crop and medicinal plant, the

5 therapeutic potential of which was known to the ancient Egyptians, Greeks, and Romans

6 (Lattanzio et al., 2009). In the remote past artichoke preparations were used as a digestive aid. In

7 recent times, reports from folk medicine as well as preliminary data from scientifically designed

8 clinical studies have suggested that artichokes may have cholerectic, hypocholesterolemic, and

9 hypolipidemic properties (Gebhart, 1998; English et al., 2000; Bundy et al., 2008; Wider et al.

10 2009; Küskü-Kiraz et al., 2010).

11 Based on the notion that dietary fibers may be beneficial in carbohydrate metabolism a recent

12 study (Vinik et al., 1998) found that consumption of an artichoke food supplement for three

13 consecutive months reduced fasting and post-prandial glycemia in type-2 diabetic patients (Nazni

14 et al., 2006). Consistently, an independent study found that a meal of bread and wild artichokes

15 (Cynara cardunculus L.) attenuated post-prandial increase in glycemia in healthy subjects

16 (Nomikos et al., 2007).

17 The present study was designed to assess the ability of artichoke extract to reduce glycemia via a

18 mechanism other than the action of its fibers (Vinik et al., 1998). For this purpose, the present

19 study tested the capacity of a standardized, purified, fiber-free extract of Cynara scolymus L. to

20 lower post-prandial glycemia in laboratory rats. This extract was of particular interest with regard

21 to the study aims as it was completely fiber-free. Two different strains of rats were used:

22 unselected Wistar rats and genetically selected, obese Zucker rats; notably, Zucker rats display

23 fasting hyperglycemia and have been proposed as a possible animal model of pre-diabetes

24 (Romanovsky et al., 2008). The effect of the acutely administered artichoke extract on glycemia

25 was evaluated after the consumption of a large meal comprising a given amount of food. Rats were 
1 fasted before the meal to ensure consumption of an equal amount of food by rats from each

2 experimental group (vehicle- or extract-treated rats) within the scheduled 1-hour access period. 3

\section{Materials and Methods}

7 The experimental procedures employed in the present study were in accordance with the European

8 Communities Council Directive (86/609/EEC) and the subsequent Italian Law on the Protection of 9 animals used for experimental and other scientific reasons.

\section{Animals}

13 Adult male Wistar (Experiment 1) and Zucker (Experiment 2) rats (Charles River Laboratories, 14 Calco, LC, Italy) were used. In both experiments rats were individually housed in standard plastic 15 cages with wood chip bedding. The animal facility was under an inverted 12:12 hour light-dark 16 cycle (lights on at 11:00 p.m.), at a constant temperature of $22 \pm 2^{\circ} \mathrm{C}$ and relative humidity of 17 approximately $60 \%$. Rats were extensively habituated to handling, intragastric infusion, and blood 18 drawing from the tail tip.

20 Extract preparation

22 Cynara scolymus flowering heads, Sardinian spiny variety, were chopped and frozen at the time of 23 harvesting. The biomass, maintained at $-30^{\circ} \mathrm{C}$ until extraction, was cryoground and immediately 24 submitted to alcoholic extraction. $1 \mathrm{~kg}$ of Cynara scolymus flowering heads was extracted in a 25 percolator with ethanol/water (70:30), using a total volume of 7 L. The hydroethanolic extract was 26 concentrated under vacuum, to remove ethanol, obtaining $1 \mathrm{~L}$ of an aqueous concentrate, a volume 
1 corresponding to that of extracted plant material. Subsequently, the concentrate was purified on an 2 absorption resin through loading into a column packed with $900 \mathrm{~mL}$ polymeric resin 3 (Amberlite $\left.{ }^{\mathrm{TM}}\right)$; the resin was thoroughly washed with $1 \mathrm{~L}$ water, the purified extract eluted with 2

4 L ethanol, and was subsequently concentrated to dryness to yield $8.5 \mathrm{~g}$ of powder. Separation and 5 determination of caffeoylquinic acid derivatives and flavonoids in the extract was performed 6 simultaneously by a reversed phase HPLC method, using a stainless steel column (250 x $4.6 \mathrm{~mm})$, 7 packed with octadecylsilyl silica gel for chromatography $(5 \mu \mathrm{m})$, kept at $20^{\circ} \mathrm{C}$, and with gradient 8 elution at a constant flowrate of $1.0 \mathrm{ml} / \mathrm{min}$. Mobile phase A was composed by a mixture of 9 trifluoroacetic acid $(0.01 \% \mathrm{v} / \mathrm{v}$, in water); mobile phase $\mathrm{B}$ was composed by a mixture of 10 trifluoroacetic acid $(0.01 \% \mathrm{v} / \mathrm{v}$, in acetonitrile); the injection volume for all samples was $10 \mu \mathrm{l}$. 11 Detection was obtained with a UV spectophotometer at $263 \mathrm{~nm}$. Samples and standards were 12 dissolved in methanol ( $40 \% \mathrm{v} / \mathrm{v}$, in water), filtered by a $0.45-\mu \mathrm{m}$ polytetrafluoroethylene syringe 13 filter and then injected directly into the HPLC system. The extract obtained had a high 14 caffeoylquinic acid $(\geq 50 \%)$, and flavonoid content, expressed as luteolin glycosides, of 15 approximately $2 \%$.

\section{Experimental procedure}

19 In both experiments, rats were kept under a regimen of unlimited access to regular rodent chow 20 [Harlan, Global Diet 2018, Mucedola, Settimo Milanese, MI, Italy; main composition: 18.9\% 21 crude protein, $5.7 \%$ crude oil, $3.8 \%$ crude fibre, $5.9 \%$ ash, $57.3 \%$ carbohydrate $(42.2 \%$ starch, $224.9 \%$ sugar); digestible energy: $3.35 \mathrm{cal} / \mathrm{g}$, metabolisable energy: $3.27 \mathrm{cal} / \mathrm{g}$ ] and water for 24 23 hours/day. Rats were fasted 12 hours before the start of the experiment (this 12-hour period 24 coincided with the entire light phase of the light-dark cycle). In Experiment 1, on the test day 25 Wistar rats were divided into four groups of $n=7-9$, matched for body weight and glycemia at time 26 , and treated with 0, 500, 1000, and $1500 \mathrm{mg} / \mathrm{kg}$ Cynara s. flowering head extract. In Experiment 
12 , on the test day Zucker rats were divided into three groups of $n=6-7$, matched for body weight

2 and glycemia at time 0, and treated with 0, 500, and $1500 \mathrm{mg} / \mathrm{kg}$ Cynara s. flowering head extract.

3 Doses of Cynara s. flowering head extract were selected on the basis of the results of previous

4 experiments and literature data (Küskü-Kiraz et al., 2010). In both experiments, Cynara s.

5 flowering head extract was suspended in distilled water with a few drops of Tween 80 and

6 administered intragastrically by a metal gavage at an infusion volume of $4 \mathrm{ml} / \mathrm{kg}, 30 \mathrm{~min}$ before

7 lights off. At lights off, rats were given $8 \mathrm{~g} / \mathrm{kg}$ food pellets; this food amount was chosen on the

8 basis of preliminary experiments demonstrating how fasted Wistar and Zucker rats consumed this

9 entire amount in less than 60 min (this laboratory, unpublished results). Glycemia was determined

$100,60,120$, and $360 \mathrm{~min}$ after food presentation. A small $(0.05 \mathrm{ml})$ blood sample was collected

11 from the tip of the tail of each rat and analyzed enzymatically by means of GL5 Analox (Analox

12 Ltd, London, United Kingdom).

13

14 Statistical analysis

15

16 In both experiments, data on the effect of Cynara s. flowering head extract on time-course of

17 glycemia were analyzed by a 2-way (dose; time) ANOVA with repeated measures on the factor

18 "time". Data on the effect of Cynara s. flowering head extract on the area under the curve of the

19 time-course of glycemia [expressed in $\mathrm{mg} * \mathrm{~min} / 100 \mathrm{ml}$; calculated using GraphPath Prism 3.03

20 (GraphPath Software, La Jolla, CA, USA)] were analyzed by a 1-way ANOVA.

21

22

$23 \quad$ Results

24

25

Experiment 1 (Wistar rats)

26 
1 Glycemia in fasted Wistar rats averaged approximately $70 \mathrm{mg} / \mathrm{dl}$ in all rat groups (Figure 1, top

2 panel). In vehicle-treated rats, meal consumption resulted in an increase of glycemia at both the

3 60- and 120-min recording times, when it averaged approximately $130 \mathrm{mg} / \mathrm{dl}$ (Figure 1, top panel).

4 At the 360-min recording time, glycemia in vehicle-treated rats approached basal levels (Figure 1,

5 top panel).

6 ANOVA revealed a highly significant effect of treatment with Cynara s. flowering head extract on

7 post-prandial glycemia over the 6-hour recording period $\left[\mathrm{F}_{\text {dose }}(3,30)=7.44, \mathrm{P}<0.001\right.$;

$\left.8 \quad \mathrm{~F}_{\text {time }}(2,60)=129.31, \mathrm{P}<0.0001 ; \mathrm{F}_{\text {interaction }}(6,60)=1.22, \mathrm{P}>0.05\right]$. At the 60 - and 120 -min recording

9 times, all three doses of Cynara s. flowering head extract produced a marked decrease in glycemia

10 (Figure 1, top panel). Glycemia increase (expressed as percentage of values recorded in fasted rats

11 at time 0) averaged approximately $85 \%, 65 \%, 60 \%$, and $50 \%$ in $0,500,1000$, and $1500 \mathrm{mg} / \mathrm{kg}$

12 Cynara s. flowering head extract-treated rats, respectively, with negligible differences between the 13 60- and 120-min recording times (Figure 1, top panel).

14 In close agreement with the above results, treatment with Cynara s. flowering head extract also 15 reduced the area under the curve of glycemia time-course $[\mathrm{F}(3,30)=7.23, \mathrm{P}<0.001]$ (Figure 1 , 16 bottom panel).

18 Experiment 2 (Zucker rats)

20 Glycemia in fasted Zucker rats averaged approximately $105 \mathrm{mg} / \mathrm{dl}$ in all rat groups (Figure 2, top 21 panel). In vehicle-treated rats, meal consumption resulted in an increase of glycemia at all three 22 recording times; it rose to $150 \mathrm{mg} / \mathrm{dl}$ at the 60 -min recording time and declined slowly, being 23 approximately $135 \mathrm{mg} / \mathrm{dl}$ at the 360-min recording time (Figure 2, top panel).

24 ANOVA revealed a significant effect of treatment with Cynara s. flowering head extract on post25 prandial glycemia over the 6-hour recording period $\left[\mathrm{F}_{\text {dose }}(2,16)=5.22, \mathrm{P}<0.05 ; \mathrm{F}_{\text {time }}(2,32)=1.09\right.$, $\left.26 \mathrm{P}>0.05 ; \mathrm{F}_{\text {interaction }}(4,32)=0.06, \mathrm{P}>0.05\right]$. At the 60 -min recording time, both doses of Cynara s. 
1 flowering head extract tended to reduce the glycemia (Figure 2, top panel). At the following time

2 intervals (120 and $360 \mathrm{~min}$ ) a decrease in glycemia was observed only in the rat group treated with

$31500 \mathrm{mg} / \mathrm{kg}$ Cynara s. flowering head extract (Figure 2, top panel).

4 Accordingly, treatment with Cynara s. flowering head extract reduced the area under the curve of 5 glycemia time-course $[\mathrm{F}(2,16)=4.60, \mathrm{P}<0.05]$ (Figure 2, bottom panel).

\section{Discussion}

8

9 The results of the present study indicate that the acute administration of a standardized extract of 10 Cynara s. flowering heads effectively reduced post-prandial increase in glycemia in two different 11 strains of rats, unselected Wistar and genetically obese Zucker rats. The experiment was designed 12 to oblige rats to consume large amounts of food (a regular rat chow made up of $57.3 \%$

13 carbohydrates) in a single meal; to this end, rats were initially fasted and then given the maximum 14 amount of food that rats of both strains were able to consume entirely over a 1-hour period. In 15 Wistar rats the effect of Cynara s. flowering head extract produced a negligible dose-dependence 16 relationship. Additional studies should be undertaken to investigate whether alternative vehicles 17 may improve extract absorption resulting in a higher degree of separation between the effects of 18 the different doses.

19 To our knowledge, the results of the present study constitute the first experimental evidence of the 20 reducing effect of an artichoke preparation on glycemia in laboratory rodents. These results are 21 consonant with recent human studies reporting the capacity of dietary artichoke (both Cynara 22 scolymus L. and Cynara cardunculus L.) to lower post-prandial rise of glycemia in humans (Nazni 23 et al., 2006; Nomikos et al., 2007).

24 In the present study, potency and efficacy of Cynara s. flowering head extract tended to be higher 25 in Wistar than Zucker rats. The reason for this difference is unknown at present and may require 26 further investigation. 
1 The present investigation did not specifically address the mechanism(s) of action and/or the active

2 principle(s) by which Cynara s. flowering head extract exerted its reducing effect on glycemia. At

3 present, we can however rule out the hypothesized contribution of fibers contained in dietary

4 artichokes (Nazni et al., 2006; Nomikos et al., 2007), as the extract used in this investigation was

5 completely purified and devoid of any fiber content. Additional studies are needed to investigate

6 mechanism(s) of action, active principle(s), and changes in levels of hormones in specific tissues,

7 including pancreas, liver, gut, muscle, and adipose tissue.

8

9

10

Acknowledgements

12

13 The present study was funded by Italian National Research Council [Consiglio Nazionale delle

14 Ricerche (CNR)], and Indena S.p.A., Milan, Italy.

15

16

17

18

19

20

21

22

23

24

25

26 


\section{$1 \quad$ References}

2

3 Bundy R, Walzer AF, Middelton RW, Wallis C, Simpson HC. 2008. Artichoke (Cynara

4 scolymus) reduces plasma cholesterol in otherwise healthy hypercholesterolemic adults: a

5 randomized, double blind placebo controlled trial. Phytomedicine 15: 668-675

6

7 Englisch W, Beckers C, Unkauf M, et al. 2000. Efficacy of Artichoke dry extract in patients 8 with hyperlipoproteinemia. Arzneimittelforschung 50: 260-265.

9

10 Gebhardt R. 1998. Inhibition of cholesterol biosynthesis in primary cultured rat hepatocytes 11 by Artichoke (Cynara scolymus L.) extracts. J Pharmacol Exp Ther 286: 1122-1128.

13 Küskü-Kiraz Z, Mehmetçik G, Dogru-Abbasglu S, Uysal M. 2010. Artichoke leaf extract 14 reduces oxidative stress and lipoprotein dyshomeostasis in rats fed on high cholesterol diet. $15 \quad$ Phytoter Res . 24: 565-570.

17 Lattanzio V, Kroon PA, Linsalata V, Cardinali A. 2009. Globe artichoke: A functional food 18 and source of nutraceutical ingredients. J Function Foods 1: 131-144.

20 Nazni P, Poongodi Vijayakumar T, Alagianambi P, Amirthaveni M. 2006. Hypoglycemic and 21 Hypolipidemic Effect of Cynara scolymus among Selected Type 2 Diabetic Individuals. 22 Pakistan J Nutr 5: 147-151.

24 Nomikos T, Detopulou P, Frogopulou E, Pliakis E, Antonopoulou S. 2007. Boiled wild 25 artichoke reduces postprandial glycemic and insulinemic responses in normal subjects but has 26 no effect on metabolic syndrome patients. Nutr Res 27: 741-749. 
1

21

4

5

7

8

9

10

11

12

13

14

15

16

17

18

19

20

21

22

23

24

25

26

27

28

29

30

31

32

33

34

35

36

37

38

39

40

41

42

43

44

45

46

47

48

49

50

51

52

53

54

55

56

57

58

59

60

4

6

9

2 Romanovsky D, Walker JC, Dobretsov M. 2008. Pressure pain precedes development of type 2

3 disease in Zucker rat model of diabetes. Neuorsci Lett 445: 220-223.

5 Vinik AI, Jenkins DJ. 1998. Dietary fiber in management of diabetes. Diab Care 11: 160-173.

7 Wider B, Pittler MH, Thompson-Coon J, Ernst E. 2009. Artichoke leaf extract for treating

8 hypercholesterolaemia. Cochrane Database Syst Rev 4: CD003335. 


\section{$1 \quad$ Figure captions}

2

3

4 Figure 1 - Effect of the acute administration of a Cynara s. flowering head extract on time-course

5 of glycemia (top panel) and area under the curve of the time-course of glycemia (bottom panel) in

6 Wistar rats given a 1-hour (corresponding to the 0-60 mim time interval) access to regular rat

7 chow and water. Each bar or point is the mean \pm S.E.M. of $n=7-9$ rats. $*: P<0.05$ and $+: P<0.005$

8 with respect to the rat group treated with $0 \mathrm{mg}$ Cynara $s$. flowering head extract.

9

10 Figure 2 - Effect of the acute administration of a Cynara s. flowering head extract on time-course

11 of glycemia (top panel) and area under the curve of the time-course of glycemia (bottom panel) in

12 Zucker rats given a 1-hour (corresponding to the 0-60 mim time interval) access to regular rat

13 chow and water. Each bar or point is the mean \pm S.E.M. of $n=6-7$ rats. $*: P<0.05$ with respect to

14 the rat group treated with $0 \mathrm{mg}$ Cynara s. flowering head extract.

15 

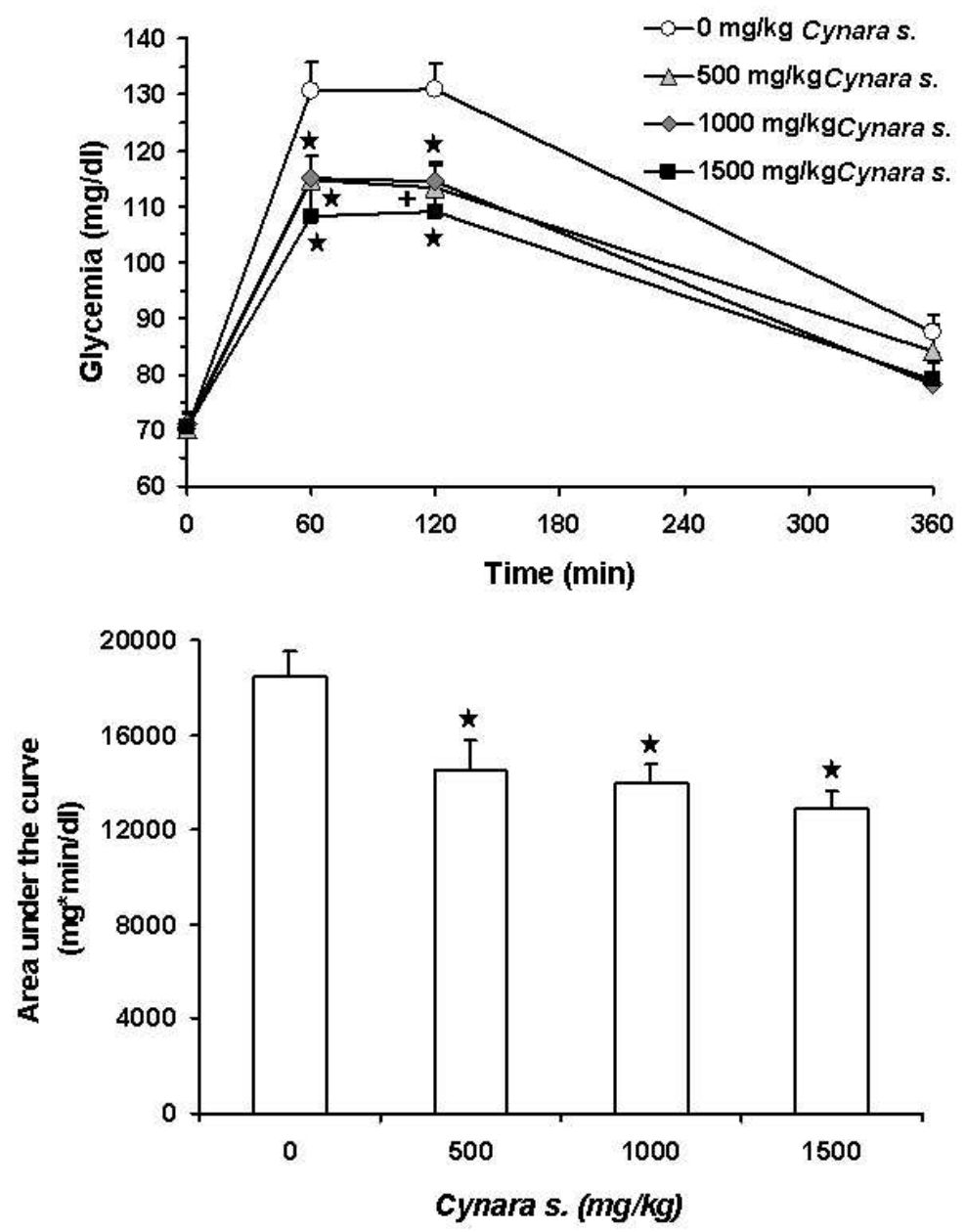

Carai et al., Figure 1

$190 \times 254 \mathrm{~mm}(96 \times 96$ DPI $)$ 


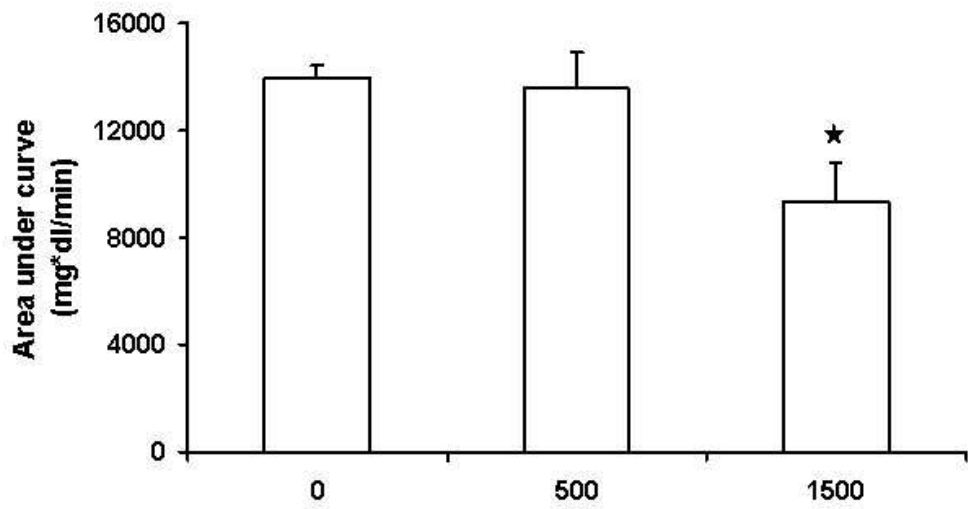

Cynara s. $(\mathrm{mg} / \mathrm{kg})$

Carai et al., Figure 2

$190 \times 254 \mathrm{~mm}(96 \times 96$ DPI $)$ 